\title{
Projected Impacts of Global Warming on Chum Salmon Stocks in Hokkaido, Japan
}

\author{
Hirokazu Urabe and Akiyoshi Shinada \\ Salmon and Freshwater Fisheries Research Institute, Hokkaido Research Organization, 3-373 Kitakashiwagi, \\ Eniwa, Hokkaido, Japan
}

Keywords: chum salmon, global warming, ocean entry period, duration of preferable sea surface temperature

In recent years, there has been a rapidly growing worldwide concern regarding the impacts of climate change on marine ecosystems. The Japan Meteorological Agency (JMA) reported that the sea surface temperature (SST) around Hokkaido has been increasing by $1^{\circ} \mathrm{C}$ per 100 years, and we are concerned about future impacts of increasing ocean temperature on the chum salmon stock in Hokkaido. Predicting the changes of ocean temperature conditions, and knowledge about how the change of ocean conditions could affect chum salmon stock, are essential if substantial measures are to be taken. To date, JMA published a long-term (100 year) forecast about trends in the variability of annual mean SST using a global climate model. However, there were issues with the forecast that were identified so that the prediction could be applied to salmon stock management in Hokkaido. The prediction is calculated as an annual mean SST, and the unit region for the prediction is larger than that used for chum salmon stock management.

We estimated the future variability of daily SST in six sea areas around Hokkaido using the JMA model (Yukimoto et al. 2012) that was developed based on the IPCC assessment report in the present study, which almost corresponds with the unit regions for chum salmon management. The estimations were targeted for 2016-2100 and were calculated based on four scenarios (RCP 2.6, 4.5, 6.0, 8.0). Using these estimations, we analyzed the future variability of the SST regime during the ocean entry period of chum salmon around Hokkaido coastal areas, and how the changes associated with climate change affect chum salmon stock in Hokkaido.

We analyzed the variabilities between start and end dates, and the duration of $8-13^{\circ} \mathrm{C}$ temperatures which is recognized as preferable SST for chum salmon juveniles in coastal areas of Hokkaido (Irie 1990, Seki 2005). Our analyses revealed that the starting and ending dates with the preferred SST were advanced and delayed in all six areas, respectively, but the variabilities of SST through the targeted period differed between areas and scenarios. The period of the preferred SST decreased in the Okhotsk and Nemuro areas and increased in the northern and southern Japan sea, as well as western Pacific areas, and no obvious change was found in the eastern Pacific area. These results suggest that while future changes of SST during the spring season due to climate change might negatively impact the early survival of chum salmon juveniles in the Okhotsk and Nemuro areas, it might positively affect their survival in the northern and southern Japan sea areas, as well as the western Pacific area.

\section{REFERENCES}

Irie, T. 1990. Ecological studies on the migration of juvenile chum salmon, Oncorhynchus keta, during early ocean life. Bull. Seikai Natl. Fish. Res. Inst. 68: 1-142. (In Japanese with English summary)

Seki, J. 2005. Study of characteristic of feeding habitat of juvenile chum salmon and their food environment in the Pacific coastal waters, central part of Hokkaido. Bull. Nat. Salmon Resources Center 7: 1-104. (In Japanese with English abstract)

Yukimoto, S., Y. Adachi, M. Hosaka, T. Sakami, H. Yoshimura, M. Hirabara, T.Y. Tanaka, E. Shindo, H. Tsujino, M. Deushi, R. Mizuta, S. Yabu, A. Obata, H. Nakano, T. Koshiro, T. Ose, and A. Kitoh. 2012. A New Global Climate Model of the Meteorological Research Institute: MRI-CGCM3-Model Description and Basic Performance. J. Meteorol. Soc. Jpn. 90A: 23-64. 